\title{
Energy and Macronutrients Intakes among Childbearing Age Women Living in the Urban Area of Morocco: A Cross-Sectional Study
}

\author{
Fatima Barich $\mathbb{D}^{1,2}$ Fatima Zahra Laamiri, ${ }^{3,4}$ Slimane Mehdad, ${ }^{5}$ Souad Benaich $\left(\mathbb{D},{ }^{5}\right.$ \\ Anass Rami, ${ }^{1}$ Mohamed Idrissi $\odot{ }^{1},{ }^{1}$ Chaimae Serbouti, ${ }^{1}$ Houria Lahmame, ${ }^{1}$ \\ Hasnae Benkirane, ${ }^{1}$ Manelle Rjimati, ${ }^{1}$ Amina Barkat, ${ }^{3}$ El Arbi Rjimati, ${ }^{1,2}$ \\ and Hassan Aguenaou ${ }^{1}$ \\ ${ }^{1}$ Joint Unit of Nutrition and Food Research, CNESTEN-Ibn Tofäıl University-URAC 39, \\ Regional Designated Center for Nutrition (AFRA/IAEA), Rabat, Morocco \\ ${ }^{2}$ Higher Institute of Nursing and Medical Professions, Rabat, Morocco \\ ${ }^{3}$ Mother and Child Couple Health and Nutrition Research Team, FMP de Rabat, Mohammed V University, Rabat, Morocco \\ ${ }^{4}$ Health Sciences and Technology Laboratory, Higher Institute of Health Sciences of Settat, Hassan First University, \\ Settat, Morocco \\ ${ }^{5}$ Physiology and Physiopathology Research Team, Faculty of Sciences, Mohammed V University, Rabat, Morocco
}

Correspondence should be addressed to Fatima Barich; barich.fatima@yahoo.fr

Received 10 May 2020; Revised 7 August 2020; Accepted 27 August 2020; Published 11 September 2020

Academic Editor: H. K. Biesalski

Copyright (C) 2020 Fatima Barich et al. This is an open access article distributed under the Creative Commons Attribution License, which permits unrestricted use, distribution, and reproduction in any medium, provided the original work is properly cited.

\begin{abstract}
Over the last few decades, there have been significant dietary and lifestyle changes worldwide. In Morocco, these changes have led to serious nutritional disorders and increased risk of morbidity and mortality particularly among vulnerable groups such as women of childbearing age. We aimed to assess the average daily energy and macronutrient intakes and to investigate their association with socioeconomic factors and weight status among women aged 19-49 years in urban areas. A total of 542 women attending public health centers were recruited. Socioeconomic and demographic data were collected using a questionnaire. Anthropometric measurements were taken using standardized equipment. Food consumption data were obtained through the 24hour dietary recall method, and the macronutrient composition of foods was estimated based on the Moroccan food composition table and the Nutrilog software. The average daily energy intake among the study population was $1591 \mathrm{kcal}$, composed of $56 \%$ from carbohydrates, $28 \%$ from fats, and $16 \%$ from protein. Reported energy intake by the majority of women (81.5\%) was lower than recommended daily allowances for energy. There was a significant positive correlation between educational level and energy $(p=0.001)$, carbohydrates $(p=0.001)$, proteins $(p=0.004)$, and fats intakes $(p=0.032)$, respectively. A significant negative association of household size with protein intakes was also observed $(p=0.034)$. Carbohydrates, proteins, and fats intakes tended to decrease; however, these associations were not statistically significant. Further studies and appropriate interventions are needed to address the trends in energy and macronutrients intakes in the development of policy initiatives aimed at nutrition education and chronic disease prevention among childbearing age women.
\end{abstract}

\section{Introduction}

Malnutrition is defined as deficiencies, excesses, or imbalances in individuals' intake of energy and/or nutrients [1]. A balanced diet can be achieved when the total energy intake is covered at 10 to $15 \%$ from protein, 15 to $30 \%$ from fat, and $50-55 \%$ from carbohydrate [2, 3]. Malnutrition is characterized by an inadequate intake of protein, energy, or micronutrients, aggravated by frequent infections or diseases $[4,5]$. It is currently the most serious nutritional problem in many countries in Asia, Latin America, the Middle East, and Africa [6]. Malnutrition 
increases health care expenditure and reduces productivity and economic growth, which can result in a cycle of poverty and poor health $[1,7]$. Women, infants, children, and adolescents are particularly most exposed to malnutrition [1].

Paradoxically, many parts of the world are currently exposed to overweight and obesity epidemic, with over 39\% of adults being overweight globally especially due to an energy imbalance that results from increased caloric intake and reduced energy expenditure [8]. Consequently, the burden of noncommunicable diseases like cardiovascular diseases, diabetes, musculoskeletal disorder, and some cancers is increasing [8-10]. The prevalence of these diseases in developing countries is increasing at an alarming rate, particularly in urban areas, and remains one of the major public health concerns $[11,12]$.

Over the last few decades, the Moroccan population has been facing rapid dietary and lifestyle changes. Changes have led to serious nutritional disorders and increased prevalence of noncommunicable diseases (NCD) in all age groups. For instance, the survey conducted in 2018 reported a high prevalence of hypertension, diabetes, and hypercholesterolemia among Moroccan women aged 18 years and over $(29.8 \%, 12.6 \%$, and $14.0 \%$, respectively) [13]. These NCDs are often associated with obesity which can also lead to many other health complications including cardiovascular and respiratory disorders $[8,10]$. Also, obesity has recently reached unprecedented prevalence $(29.0 \%)$ among women [13], which could significantly increase the risk of morbidity and mortality in this population segment, particularly among women of childbearing age.

As all Moroccan regions, Rabat-Salé-Kenitra region has been experiencing a dramatic increase in obesity prevalence rates among women during the past two decades [14]. However, to our knowledge, there is no information on energy and macronutrient intakes as important factors contributing to weight gain particularly among women of childbearing age living in this region. Thus, our study aimed to assess the average daily energy and macronutrient intakes and to investigate their association with nutritional status and socioeconomic factors among a sample of women aged 19-49 years from urban areas surrounding Rabat, the capital city of Morocco.

\section{Materials and Methods}

2.1. Population. This study is a descriptive cross-sectional survey. It was carried out on healthy women recruited from public health centers located in Rabat-Salé-Kenitra region. It included women aged 19-49 years who were not under any permanent medical treatment. Pregnant and lactating women, women suffering from mental illnesses, and those who participated in the pilot study were excluded from the current study.

2.2. Site of the Study. The study took place in urban areas of Rabat, Salé, and Skhirat-Témara prefectures known for their high rates of obesity (ENSF, 2003-2004) [14].
2.3. Selection of Health Centers. The women were recruited from 21 selected urban health centers based on the following criteria: accessibility of our field team and high participation of women to cover the number required for the age group under study.

2.4. Sample. The study included 542 Moroccan childbearing age women aged between 19 and 49 years who visited the health centers during the period of data collection. Only women who met the inclusion criteria and provided their consent to participate in the survey were recruited.

To calculate the sample size, we used the formula developed by Cochran (1977) [15] and Ardilly (2006) [16]:

$$
n=t 2 \times p \times \frac{(1-p)}{m 2},
$$

where $t$ is the $95 \%$ confidence level, $p$ is the estimated prevalence of the obese population, and $m$ is the error margin (set at $5 \%$ ).

The estimated prevalence of obesity in the targeted region was $14.4 \%$ with an error margin of 5\% [14]. Thus, 189 subjects were considered necessary for inclusion to obtain statistically representative data. The total number of women who met the inclusion criteria was 542 .

2.5. Anthropometric Parameters. The anthropometric parameters of each participant were measured according to the WHO standard procedures [17]. Body weight was measured to the nearest of $0.1 \mathrm{~kg}$ using a scale (Seca 750) with a minimum of clothing and no shoes. The height was measured to the nearest of $0.1 \mathrm{~cm}$ using a stadiometer (Seca). Body mass index (BMI) was calculated as the ratio of weight in $\mathrm{kg}$ to square height in $\mathrm{m}^{2}$. Women were classified into four groups according to BMI $[17,18]$ :

(i) Women with underweight: $\mathrm{BMI}<18.5 \mathrm{~kg} / \mathrm{m}^{2}$

(ii) Women in a normal weight range: $18.5 \mathrm{~kg} /$ $\mathrm{m}^{2} \leq \mathrm{BMI} \leq 24.99 \mathrm{~kg} / \mathrm{m}^{2}$

(iii) Overweight women: $25 \mathrm{~kg} / \mathrm{m}^{2} \leq \mathrm{BMI} \leq 29.99 \mathrm{~kg} / \mathrm{m}^{2}$

(iv) Obese women: $\mathrm{BMI} \geq 30 \mathrm{Kg} / \mathrm{m}^{2}$

Waist circumference was measured midway between the lower edge of the last palpable rib and the top of the iliac crest [19]. The hip circumference was measured at the widest point on the buttocks of the study participants. For abdominal obesity, waist-to-hip ratio (WHR) was obtained by dividing the average waist circumference by the average hip circumference. Women with WHR $\geq 0.85$ were classified as abdominally obese [17].

\subsection{Data Collection}

2.6.1. Socioeconomic and Demographic Factors. The data on socioeconomic and demographic factors were collected at the beginning of the study through direct interviews. We used an adequate questionnaire that was adapted from other ones used nationally for a similar purpose [14]. 
The collected information included women's education level, marital status, occupation, occupation of the household head, number of children, household size, household monthly global expenses, and food expenses.

\subsubsection{Dietary Intake Assessment}

(1) The 24-Hour Recall Questionnaire. Food intake data were collected using the 24 -hour recall questionnaire, a rapid and inexpensive method that could be used for nutrition surveys in large groups [20].

This questionnaire includes information related to quantity and nature of food eaten (bread, tomato, tea, water, etc.) for breakfast, lunch, and dinner as well as midmorning and midafternoon snacks.

In this study, the multipass approach was used to validate the 24-hour recall questionnaire. The principle of this method consists of 5 steps [21, 22]:

(a) Quick list: to collect a list of foods consumed the previous day.

(b) Forgotten foods list: to collect foods that may have been forgotten during the quick list. Questions probe for foods by categories: nonalcoholic beverages, alcoholic beverages, sweets, savory snacks, fruits, vegetables, cheese, bread and rolls, and other foods.

(c) Time and occasion: to collect time and name of eating occasion for each food, used to sort foods chronologically and group into eating occasions.

(d) Detail and review: to collect a detailed description of each food consumed, including the amount eaten and additions to the food, and also to review eating occasions and times between occasions to elicit forgotten foods.

(e) Final review: to collect additional foods not remembered earlier.

Women were asked to provide all information about foods and drinks consumed for two separated days using visual aids to approximate the serving sizes of various foods: a photo manual (SU.VI.MAX) for estimating consumed portions of food and drink [23] and a food book to estimate the amount of food consumed based on food and typical preparations of the Moroccan population [24].

The quantities consumed were converted using the Food Quantification Table, available in the corresponding book, then entered into the Nutrilog Food Information Software (SAS, version: 2.31, with Moroccan Food Composition Table), which was used to determine nutrients and vitamins content of each food. At the same time, all details on vitamin and mineral supplements consumed during the investigation period were noted and the average macronutrient intake over two days was reported to estimate the exact quantities permitting comparison with recommended dietary intakes.

(2) Nutrilog Software. The Nutrilog software (version 2.31) is a professional nutrition tool based on nutritional references of the ANSES (French national agency of health safety of nutrition, environment, and employment) [25]. It provides information on the individual food profile. The Moroccan food composition table has been integrated into the software database containing the CIQUAL food table, France 2012; USD SR24; USA 201 [25] provided by the supplier. It is worth mentioning that the Moroccan food composition table is the first table developed and includes 424 foods consumed in our country.

2.7. Statistical Analysis. The data matrix compiled by the Nutrilog software, combined with socioeconomic and demographic data, was analyzed with statistical software for the social sciences (SPSS version 13.0). The normality of the distribution of anthropometric and nutritional variables was assessed using the Kolmogorov-Smirnov (KS) test [26]. Continuous variables with Gaussian distribution were expressed as mean \pm standard deviation, while nonGaussian distribution variables were expressed as median (interquartile range). Categorical variables were expressed as counts and percentages. We used the Chi-square test to compare energy intake between different age groups. Pearson correlation test was used to examine the association of energy and macronutrients intakes with demographic and socioeconomic factors. Finally, the KruskalWallis test was used to compare macronutrients and energy intakes among BMI groups. A value of $p<0.05$ was considered significant.

2.8. Ethical Considerations. The study protocol was approved by the Ethics Board of the Faculty of Medicine and Pharmacy, Mohammed University in Rabat, Morocco (Ethical Approval number 69 delivered on 31 January 2017). Before data collection, invited participants were informed about the study objectives and methods, and both oral and written consent were obtained from all who were recruited.

\section{Results}

3.1. Demographic and Socioeconomic Characteristics. The demographic and socioeconomic characteristics of the study population are presented in Table 1 . The majority of women had Arab ethnic background (77.1\%). Over two-thirds were without job (70.7\%), 17.2\% were illiterate, and more than a third of women $(38.4 \%)$ had a secondary education level. Half of women (50\%) had 1 to 2 children while most families (72.0\%) were composed of 4 to 7 people. The monthly expenditure was less than US\$ 366 in $56.5 \%$ of the study population, and more than $66 \%$ spent less than US\$ 272.32 per month for food.

3.2. Anthropometric Parameters. The anthropometric parameters of the participants are presented in Table 2. The average weight and height were $67.84 \pm 13.64 \mathrm{~kg}$ and $1.60 \pm 0.06 \mathrm{~m}$, respectively. Mean values for BMI, waist circumference (WC), hip circumference (HC), and waist-tohip ratio (WHR) were $26.35 \pm 5.21 \mathrm{~kg} / \mathrm{m}^{2}, 87.60 \pm 12.98 \mathrm{~cm}$, $68 \pm 12.98 \mathrm{~cm}$, and $0.86 \pm 0.08 \mathrm{~cm}$, respectively. The 
TABle 1: Demographic and socioeconomic characteristics of the study population.

\begin{tabular}{|c|c|c|c|}
\hline Variables & $n$ & $\%$ & $95 \% \mathrm{CI}$ \\
\hline \multicolumn{4}{|l|}{ Age groups (years) } \\
\hline 19 to 29 & 240 & 44.2 & $40.4-48.5$ \\
\hline 30 to 40 & 203 & 37.5 & $33.4-41.3$ \\
\hline 41 and more & 99 & 18.3 & $15.1-21.6$ \\
\hline \multicolumn{4}{|l|}{ Ethnic background } \\
\hline Arab & 418 & 77.1 & $73.8-80.6$ \\
\hline Amazigh & 96 & 17.7 & $14.6-20.7$ \\
\hline Sahraoui & 12 & 2.2 & $1.1-3.5$ \\
\hline Rifian & 9 & 1.7 & $0.7-2.8$ \\
\hline Jebli & 7 & 1.3 & $0.2-2.4$ \\
\hline \multicolumn{4}{|l|}{ Level of education } \\
\hline Illiterate & 93 & 17.2 & $14.0-20.3$ \\
\hline Primary & 113 & 20.8 & $17.2-24.5$ \\
\hline Secondary & 208 & 38.4 & $34.3-42.8$ \\
\hline Higher education & 128 & 23.6 & $19.9-27.3$ \\
\hline \multicolumn{4}{|l|}{ Marital status } \\
\hline Single & 111 & 20.5 & $17.3-24.2$ \\
\hline Married & 405 & 74.7 & $70.8-78.2$ \\
\hline Divorced & 22 & 4.1 & $2.6-5.5$ \\
\hline Widowed & 4 & 0.7 & $0.2-1.5$ \\
\hline \multicolumn{4}{|l|}{ Occupation of women } \\
\hline Without job & 383 & 70.7 & $66.6-74.5$ \\
\hline Student & 52 & 9.6 & $7.4-12.2$ \\
\hline With job & 107 & 19.7 & $16.6-23.1$ \\
\hline \multicolumn{4}{|c|}{ Occupation of the household head } \\
\hline Without job & 16 & 3.0 & $1.7-4.4$ \\
\hline With job & 516 & 95.2 & $93.4-96.9$ \\
\hline Retired & 10 & 1.8 & $0.7-3.1$ \\
\hline \multicolumn{4}{|l|}{ Number of children } \\
\hline No child & 133 & 24.5 & $20.8-28.6$ \\
\hline 1 to 2 children & 271 & 50.0 & $45.6-53.7$ \\
\hline 3 or more & 138 & 25.5 & $22.1-29.3$ \\
\hline \multicolumn{4}{|c|}{ Monthly expenditure (US\$) } \\
\hline Lower than 122 & 4 & 0.7 & $0.2-1.7$ \\
\hline 122 to 195 & 39 & 7.2 & $5.0-9.4$ \\
\hline 196 to 244 & 144 & 26.6 & $22.9-30.4$ \\
\hline 244 to 366 & 119 & 22.0 & $18.5-25.3$ \\
\hline Higher than 366 & 124 & 22.9 & $19.2-26.4$ \\
\hline Not known & 112 & 20.7 & $17.3-24$ \\
\hline \multicolumn{4}{|c|}{ Monthly expenditure for food (US\$) } \\
\hline Lower than 65.36 & 21 & 3.9 & $2.4-5.5$ \\
\hline 65.47 to 98.03 & 55 & 10.1 & $7.7-12.7$ \\
\hline 98.14 to 130.71 & 56 & 10.3 & $7.8-12.7$ \\
\hline 130.82 to 174.28 & 132 & 24.4 & $21.0-28$ \\
\hline 174.39 to 272.32 & 97 & 17.9 & $14.8-21.4$ \\
\hline Higher than 272.32 & 69 & 12.7 & $10.1-15.7$ \\
\hline Not known & 112 & 20.7 & $17.3-24.0$ \\
\hline \multicolumn{4}{|l|}{ Household size } \\
\hline$<4$ people & 107 & 19.7 & $16.6-23.2$ \\
\hline 4 to 7 people & 390 & 72.0 & $68.1-75.6$ \\
\hline$>7$ people & 45 & 8.3 & $6.1-10.7$ \\
\hline
\end{tabular}

Note. Values are expressed in count and percentage, CI: 95\% confidence interval.

prevalence of overweight and obesity was $34.3 \%$ and $22.7 \%$, respectively, while more than $50 \%$ of women had abdominal obesity (Figure 1).
3.3. Energy and Macronutrients Intakes. Table 3 illustrates the energy and macronutrient intakes among the study population. The average daily energy intake was $1591.2 \pm 664.4 \mathrm{kcal}, 56 \%$ from carbohydrates, $28 \%$ from fats, and $16 \%$ from proteins. The majority of women (81.5\%) reported an energy intake lower than recommended daily allowances for energy, with a significant difference between age groups $(p=0.043)$.

3.4. Association of Macronutrients and Energy Intakes with Demographic and Socioeconomic Variables. Table 4 shows the correlation between energy, macronutrients, and the socioeconomic status of participants. The analysis showed a significant positive correlation between educational level and each of energy $(p=0.001)$, carbohydrates $(p=0.001)$, protein $(p=0.004)$, and fat intakes $(p=0.032)$. A negative association of household size with macronutrients and energy intakes was also observed in the study population. This association was statistically significant for protein intake $(p=0.034)$ and reached borderline statistical significance for energy and fats intakes $(p=0.080$ and $p=0.066$, respectively). Carbohydrates, proteins, and fats intakes tended to decrease as age increased; however, these associations were not statistically significant. Similarly, the correlations of macronutrients and energy intakes with other socioeconomic and demographic variables were not statistically significant.

3.5. Association of Energy and Macronutrients Intakes with Nutritional Status. Both underweight and obese women had a slightly higher average of daily energy and macronutrient intake compared to normal weight and overweight groups, but the difference was not statistically significant (Table 5).

\section{Discussion}

The present study aimed to provide information on the nutritional status of childbearing age women living in urban areas of the Rabat-Salé-Kenitra region. To our knowledge, it was the first time to estimate macronutrient and energy intakes and investigate their association with weight status and demographic and socioeconomic factors among this age group at both regional and national level, using three dietary assessment tools (food survey $(24 \mathrm{~h}$ recall), Nutrilog software, and Moroccan food composition table).

Our results showed that $34.3 \%$ and $22.7 \%$ of women were overweight and obese, respectively. These prevalence remains high compared to those reported in a previous national survey published in 2005 [14]. Similarly, obesity prevalence was greater than that reported in 2016 (19.97\%) by the High Commission for Planning (HCP) [27] but remains lower than those observed in other regions in Morocco $[28,29]$ as well as in Tunisia [30]. Furthermore, based on the WHO standards [19], we found that $50.4 \%$ of women were abdominally obese. Our results are consistent with those reported in a recent similar study indicating a high prevalence of abdominal obesity in women of childbearing age [31] and confirm the rising trends of overall and 
TABLE 2: Age and anthropometric characteristics of the study population.

\begin{tabular}{|c|c|c|c|c|}
\hline & Mean & Error standard & 95\% confidence interval & Minimum-maximum \\
\hline Age (years) & $31.96 \pm 8.42$ & 0.36 & - & $19-49$ \\
\hline Weight (kg) & $67.84 \pm 13.64$ & 0.59 & - & $39-128$ \\
\hline Height $(\mathrm{cm})$ & $1.60 \pm 0.06$ & 0.01 & - & $1.42-1.78$ \\
\hline BMI $\left(\mathrm{kg} / \mathrm{m}^{2}\right)$ & $26.35 \pm 5.21$ & 0.22 & - & $15.73-42.06$ \\
\hline \multicolumn{5}{|l|}{$B M I$ group } \\
\hline Underweight group & $29(5.4 \%)$ & 1.0 & $3.7-7.4$ & \\
\hline Normal group & $204(37.6 \%)$ & 2.1 & $33.4-41.7$ & \\
\hline Overweight group & $186(34.3 \%)$ & 2.1 & $30.3-38.4$ & \\
\hline Obesity group & $123(22.7 \%)$ & 1.8 & $19.2-26.4$ & \\
\hline $\mathrm{WC}(\mathrm{cm})$ & $87.60 \pm 12.98$ & 0.56 & - & $57-128$ \\
\hline $\mathrm{HC}(\mathrm{cm})$ & $101.68 \pm 12.98$ & 0.47 & - & $43-135$ \\
\hline WHR & $0.86 \pm 0.08$ & 0.01 & - & $0.64-1.52$ \\
\hline
\end{tabular}

Notes. Values are expressed as mean \pm standard deviation or number and percent. For groups with a body mass index (BMI): underweight, BMI $\leq 18.5 \mathrm{~kg} / \mathrm{m}^{2}$; normal BMI $=18.5$ to $<25 \mathrm{~kg} \mathrm{~m}^{2}$; overweight BMI $=25$ to $<30 \mathrm{~kg} / \mathrm{m}^{2}$; obese BMI $\geq 30 \mathrm{~kg} / \mathrm{m}^{2}$. WC: waist size $<80 \mathrm{~cm}$; HC: hip circumference $<88 \mathrm{~cm} ;$ WHR: waist $/$ hips ratio $\geq 0.85 \mathrm{~cm}$.

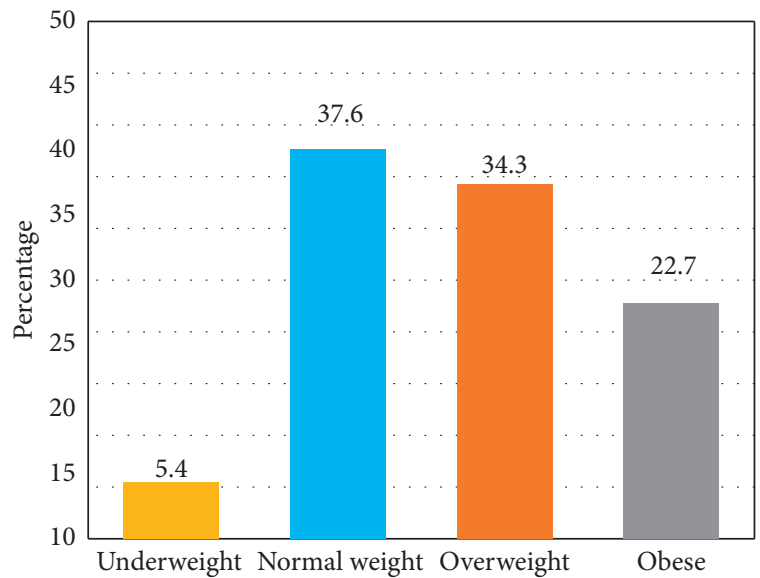

(a)

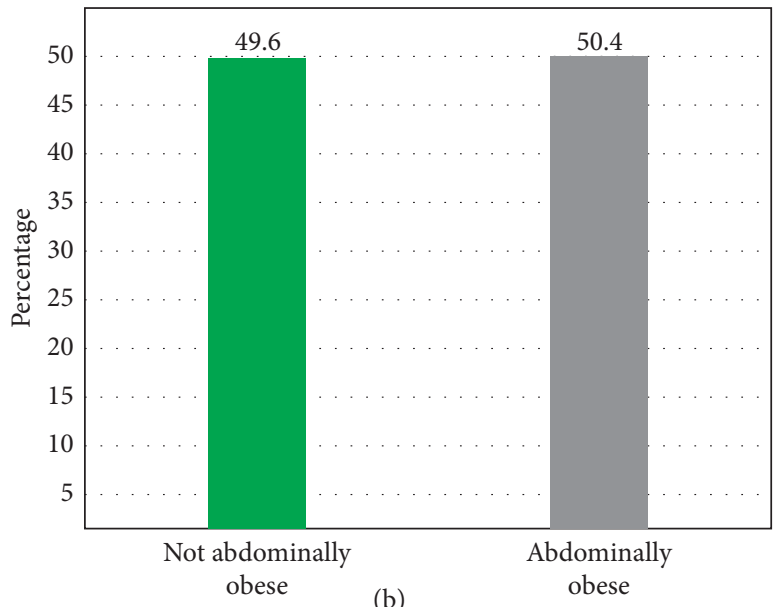

(b)

Figure 1: Prevalence of overall obesity, overweight (a), and abdominal obesity (b) among the study population. (a) BMI groups. (b) WHR groups.

TABle 3: Average daily energy and macronutrients intakes by age groups.

\begin{tabular}{|c|c|c|c|c|}
\hline Variables & 19 to 29 years $(n=240)$ & 30 to 40 years $(n=203)$ & 41 years and more $(n=99)$ & All $(n=542)$ \\
\hline Energy $(\mathrm{kcal} / \mathrm{d})^{\alpha}$ & $1648.4 \pm 740.7$ & $1543.9 \pm 587.3$ & $1549.8 \pm 611.3$ & $1591.2 \pm 664.4$ \\
\hline Underconsumption compared to $\mathrm{EER}^{\beta}$ & $184(76.7)$ & $175(86.2)$ & $83(83.8)$ & $442(81.5)$ \\
\hline Overconsumption relative to $\mathrm{EER}^{\beta}$ & $56(23.3)$ & $28(13.8)$ & $16(16.2)$ & $100(18.5)$ \\
\hline Protein $(\mathrm{g})^{\alpha}$ & $63.8 \pm 34.2$ & $59.6 \pm 31.0$ & $59.6 \pm 28.7$ & $61.5 \pm 32.1$ \\
\hline Animal protein $(g)^{\gamma}$ & $13.0[3.7-26.0]$ & $11.1[2.7-26.2]$ & $9.3[2.0-25.9]$ & $11.7[3.2-25.9]$ \\
\hline Vegetable protein $(\mathrm{g})^{\gamma}$ & $40.4[27.9-58.9]$ & $36.4[25.3-52.4]$ & $40.4[26.4-49.7]$ & $38.9[26.5-55.1]$ \\
\hline$\%$ of protein in energy intake ${ }^{\alpha}$ & $15.7 \pm 4.4$ & $15.4 \pm 4.8$ & $15.6 \pm 4.3$ & $15.6 \pm 4.5$ \\
\hline Carbohydrates $(\mathrm{g})^{\alpha}$ & $225.0 \pm 99.7$ & $211.0 \pm 77.0$ & $220.0 \pm 84.1$ & $218.8 \pm 89.0$ \\
\hline$\%$ of carbohydrates in energy intake ${ }^{\alpha}$ & $55.8 \pm 10.6$ & $55.7 \pm 10.7$ & $57.6 \pm 10.5$ & $56.1 \pm 10.6$ \\
\hline Fat $(g)^{\alpha}$ & $54.7 \pm 36.9$ & $51.3 \pm 33.9$ & $47.8 \pm 31.2$ & $52.1 \pm 34.8$ \\
\hline$\%$ of fat in energy intake ${ }^{\alpha}$ & $28.3 \pm 10.0$ & $28.9 \pm 10.9$ & $26.7 \pm 10.6$ & $28.2 \pm 10.4$ \\
\hline Saturated fatty acids $(\mathrm{g})^{\beta}$ & $26.5[20.1-33.6]$ & $25.0[19.60-34.90]$ & $25.0[19.4-34.2]$ & $7.4 \pm 6.8$ \\
\hline$\%$ of fatty acids in energy intake ${ }^{\gamma}$ & $6.9[5.1-9.4]$ & $6.81[5.2-9.10]$ & $6.6[4.9-8.2]$ & $7.4 \pm 3.8$ \\
\hline Polyunsaturated fatty acids $(\mathrm{g})^{\gamma}$ & $15.6[11.3-23.5]$ & $14.0[10.8-20.9]$ & $15.0[11.6-21.7]$ & $4.7 \pm 4$ \\
\hline$\%$ of polyunsaturated fat in energy intake ${ }^{\gamma}$ & $4.1[2.9-5.8]$ & $3.8[2.9-5.5]$ & $3.9[2.6-5.3]$ & $4.7 \pm 2.9$ \\
\hline
\end{tabular}

Note. $\alpha$ values are expressed as mean \pm standard deviation; $\beta$ values are expressed as count and percent; $\gamma$ values are expressed as median (quartiles). EER: estimated energy requirement. 
TABLE 4: Association of energy and macronutrients intakes with weight status and demographic and socioeconomic factors among the study population.

\begin{tabular}{|c|c|c|c|c|c|c|c|c|}
\hline & \multicolumn{2}{|c|}{ Energy (kcal/d) } & \multicolumn{2}{|c|}{ Carbohydrates (g) } & \multicolumn{2}{|c|}{ Protein $(\mathrm{g})$} & \multicolumn{2}{|c|}{ Fat $(\mathrm{g})$} \\
\hline & $r$ & $p$ & $r$ & $p$ & $r$ & $p$ & $r$ & $p$ \\
\hline Age & 0.069 & 0.106 & -0.055 & 0.200 & -0.058 & 0.177 & -0.065 & 0.133 \\
\hline Ethnic background & -0.013 & 0.757 & -0.035 & 0.414 & -0.016 & 0.714 & 0.007 & 0.879 \\
\hline Education level & $0.138^{* *}$ & 0.001 & $0.148^{* *}$ & 0.001 & $0.125^{*}$ & 0.004 & $0.092^{*}$ & 0.032 \\
\hline Marital status & -0.021 & 0.623 & -0.038 & 0.374 & 0.019 & 0.651 & -0.018 & 0.682 \\
\hline Women's occupation & 0.009 & 0.828 & 0.006 & 0.897 & 0.043 & 0.315 & 0.006 & 0.883 \\
\hline Size of household & -0.075 & 0.080 & -0.046 & 0.286 & $-0.091^{*}$ & 0.034 & -0.079 & 0.066 \\
\hline Monthly expenditure & -0.014 & 0.741 & 0.040 & 0.352 & 0.038 & 0.378 & -0.036 & 0.402 \\
\hline Monthly expenditure for food & -0.005 & 0.915 & 0.055 & 0.200 & -0.017 & 0.698 & -0.042 & 0.335 \\
\hline
\end{tabular}

Note. $\alpha$ values are expressed as mean \pm standard deviation; $\beta$ values are expressed as count and percent; $\gamma$ values are expressed as median (quartiles). EER: estimated energy requirement.

TABLE 5: Association of energy and macronutrients intakes with nutritional status.

\begin{tabular}{lccccc}
\hline Variables & Underweight $(n=29)$ & Normal weight $(n=204)$ & Overweight $(n=186)$ Obese $(n=123) p$ value* \\
\hline Energy $(\mathrm{kcal} / \mathrm{d})^{\alpha}$ & $1744.0[1308.5-2183]$ & $1497.0[1155.5-1957.5]$ & $1501.5[1174-1924]$ & $1546.0[1194-1924]$ & 0.350 \\
Carbohydrates $(\mathrm{g})^{\alpha}$ & $54.0[33.6-70.75]$ & $46.3[28.87-65.27]$ & $44.6[27.8-66.12]$ & $48.6[24.5-69.70]$ & 0.707 \\
\hline
\end{tabular}

${ }^{\alpha}$ Values are expressed as median and quartiles. *The Kruskal-Wallis test was used to compare medians between BMI groups.

abdominal obesity in the Moroccan population, particularly among women of childbearing age.

Moreover, as excess body weight is recognized as an important risk factor for many noncommunicable diseases $[8,9,32]$, our findings confirm also the possible role of overweight and obesity in the rapidly growing burden of these diseases whose economic cost represents about $14 \%$ of the total health expenditure in Morocco [33].

Despite all the efforts made at the national, regional, and international levels, malnutrition remains a major health problem in the EMRO region and its health consequences are too important to be neglected [34]. Many studies in Morocco have been conducted to determine the magnitude of malnutrition in different age groups such as infants and preschool children, but few of them explored its impact on women of childbearing age. In this study, the majority of women (81.5\%) did not meet the daily energy intake $(2140 \mathrm{kcal})$ recommended by the Food and Agriculture Organization of the United Nations (FAO) [35]. Assuming that the estimates of intake are correct, as most of the participants (57\%) were either overweight or obese, this is likely due to reducing dietary energy intake or caloric restriction in order to lose weight or prevent excess weight gain. Moreover, the low daily energy intake could be attributed to using the 24-hour dietary recall which may lead to underestimating the actual consumption of nutrients and foods [36], especially among overweight or obese individuals who tend to underreport their energy intake [37, 38]. Underreporting also remains one of the most common types of errors, known as "flat slope syndrome" where people generally tend to increase their intake when it is low and decrease it when it is high [39]. Other factors could influence the accuracy of self-reported nutrient and energy intake such as sex and body image perception. Studies have shown that energy misreporting is more often associated with female gender [40-42], as well as with body image dissatisfaction [40]. Likewise, some researchers have suggested that this double burden of malnutrition could also be explained by the possibility that the biological characteristics of these individuals make them more predisposed to a rapid increase in adiposity [43]. Our results support the hypothesis that using a combination of methods, such as the 24-hour dietary recall and biomarker levels, may provide more accurate estimates of the dietary intake than that of individual methods [44]. However, further research is required to assess dietary intake and investigate the impact of energy under- and overreporting on diet-obesity relationships in this population.

Similarly, the daily protein intake of our study population $(61.5 \pm 32.1 \mathrm{~g})$ was lower than that found in similar age groups from South Africa and Kuwait (125.3 g and $67.4 \pm 2.3 \mathrm{~g}$, respectively) $[45,46]$, but it provided around $16 \%$ of energy intake, which is in line with the $15 \%$ recommended by the international community for women of childbearing age $[47,48]$. Moreover, our results are consistent with those found by Zaghloul et al. among Kuwaiti women [46].

Protein intake was dominated by vegetable proteins that accounted for more than two-thirds of the daily protein intake in our study population. Although it is difficult to compare our results with those found by other studies because of their great variability. Our findings are in agreement with those reported by Steyn et al. who found a low contribution of proteins to energy intake in Kenyan women, particularly for animal protein intake [45]. However, these findings differ from those of other authors, such as Souza et al. who observed a higher intake of animal proteins among Brazilian women [49]. Given the physiological role of animal proteins and human body needs [50], the imbalance between nutrient requirements (50\% of animal proteins-50\% of plant proteins) [10] and nutrient intake observed in our study 
could have negative effects on women's health. Indeed, the predominance of vegetable proteins may prevent the human body from covering its essential amino acid needs $[10,51]$. It may also inhibit the absorption of some micronutrients such as hemic iron and zinc [52]. Thus, despite the dietary diversity and food resources available in the Rabat-SaléKenitra region, including fisheries resources [53, 54], there is a need to improve the quality and quantity of protein-rich foods to have a healthy and balanced diet among women of reproductive age.

Regarding carbohydrates, the estimated daily intake was $218.89 \pm 89.05 \mathrm{~g}$ and it accounted for an average of $56 \%$ of the mean daily energy intake. This amount exceeded both the recommended daily carbohydrates intake $(130 \mathrm{~g} / \mathrm{d})$ and its contribution to energy requirements (50-55\% from carbohydrates) [4]. Our findings are consistent with the FAO's claim that the main source of energy for most Africans, Asians, and South Americans is carbohydrates [35]. These findings also showed that current dietary patterns of our study population are characterized by elevated carbohydrates intake which may cause a loss of the diet palatability by an excessive reduction of lipid consumption [51] and that increases the risk of developing obesity and related chronic diseases [55]. Thus, our study suggests that increased education about a balanced diet and healthy eating practices is necessary to ensure the recommended percentage contribution of calories from macronutrients, particularly carbohydrate calories that should not exceed $55 \%$ of total energy intake [51].

The average fat intake was $52.2 \pm 34.8 \mathrm{~g}$ and its contribution to the average daily energy intake was $28 \%$. This contribution corresponds to the internationally recommended rate $(15-30 \%)[47,48]$. The saturated fat intake expressed as a percentage of total energy intake (E) was $7.4 \pm 3.8<10 \%$. These results are consistent with the WHO recommendations. The saturated fatty acids contribution to the daily energy intake of our study population was also lower than that of a similar study conducted among Kenyan women living in urban areas (12\%) [45]. Nevertheless, the intake of polyunsaturated fats observed in our study was $4.7 \pm 2.9 \%$. It remains relatively low to have significant health benefits, since the reduced level of this nutrient is associated with an increased risk of cardiovascular disease [56] and high levels of LDL cholesterol [57].

In the current study, a significant positive association of education level with energy, carbohydrate, protein, and fat intakes was observed. Our results are in agreement with those reported by Fryar et al. who observed a similar correlation between energy intake and education level among American women of Mexican origin [58], while they are not consistent with those of a study conducted among Kuwaiti women [46]. Overall, this correlation may be due, at least in part, to improved socioeconomic status and easy access to energy-dense foods among more educated women in Morocco.

Our results revealed a negative correlation between household size and protein intake, which confirm results reported by other authors $[59,60]$. Although the relationship between household size and socioeconomic status was not examined in this study, the observed correlation may be a result of less advantaged socioeconomic living conditions of larger family sizes.

Regarding the association of weight status with energy and macronutrient intakes, we found no statistically significant difference between various BMI groups. In agreement with our results, a previous study has shown an inconsistent association between energy and macronutrient intakes and increased BMI among Thai urban women [61]. However, many other studies demonstrated direct positive associations of energy and sugars with excess body weight $[62,63]$. As it is widely recognized that body weight gain occurs when energy intake exceeds energy expenditure, our findings could be explained by the relatively low daily energy intake among the study population.

The present study has certain limitations. First, our findings are based on the 24-hour dietary recall method and the associated underreporting of energy and macronutrient intakes is a well-documented problem of such dietary assessment tools. Second, the cross-sectional design of the study makes it impossible to draw causal relationships between different variables. However, this study provides data that can help advance knowledge about the association of dietary variables with weight status and socioeconomic factors and show to researchers and nutrition policymakers the importance of addressing macronutrient and energy intake in nutritional status research, which is very relevant in light of the current global obesity epidemic.

In conclusion, most women did not meet the recommended daily energy intake. The daily macronutrient and energy intakes were positively associated with educational level. In contrast, there was a negative association of household size and age with carbohydrate, protein, and fat intakes. Despite the low average energy intake, more than half $(57 \%)$ of the study population was either overweight or obese. These results emphasize the need for interventions to improve the dietary intake in nutritionally vulnerable women. Considering the role of overweight and obesity as major risk factors for many chronic diseases [10, 64], our findings also suggest to put in place appropriate strategies to prevent and control the double burden of malnutrition and noncommunicable diseases which remain the leading causes of death (78\%) in Morocco [65]. However, further studies are warranted to address the double burden of malnutrition and its risk factors in women of various socioeconomic groups living in urban areas.

\section{Abbreviations}

NCD: Noncommunicable diseases

BMI: $\quad$ Body mass index

WC: Waist circumference

HC: $\quad$ Hip circumference

WHR: Waist-to-hip ratio

HCP: High commission for planning

SPSS: Statistical Package for the Social Sciences

EMRO: Eastern Mediterranean regional office. 


\section{Data Availability}

Access to data is restricted in order to respect the rights of third parties and the confidentiality of participants.

\section{Conflicts of Interest}

The authors declared no potential conflicts of interest with respect to the research, authorship, and/or publication of this paper.

\section{Acknowledgments}

The authors thank all the women who participated in this study and also thank all the staff of the urban health centers of prefectures.

\section{References}

[1] World Health Organization, Factsheet: Malnutrition, World Health Organization, Geneva, Switzerland, 2018.

[2] Institute of Medicine, Dietary, Reference Intakes for Energy, Carbohydrate, Fiber, Fat, Fattyacids, Cholesterol, Protein, and Amino Acids, FNB: National Academy of Sciences, Washington, DC, USA, 2005, http://www.nap.edu.

[3] World Health Organization, Diet, Nutrition and the Prevention of Chronic Diseases, World Health Organization, Geneva, Switzerland, 2003, https://www.who.int/dietphysicalactivity/ publications/trs916/en/gsfao_introduction.pdf.

[4] Nutrition for Health and Development (NHD), Sustainable Development, and Healthy Environment, (SDE), and World Health Organization (WHO), Turning the Tide of Malnutrition, Responding to the Chalenge of the 21st Century, Nutrition for Health and Development (NHD), Geneva, Switzerland, 2000, http://apps.who.int/iris/bitstream/10665/ 66505/1/WHO_NHD_00.7.pdf.

[5] B. Baudin, "Malnutrition et sous-alimentation," Revue Francophone des Laboratoires, vol. 2014, no. 466, pp. 25-37, 2014.

[6] M. C. Latham, La nutrition dans les pays en développement, FAO, Quebec, Canada, 2001, http://www.fao.org/3/W0073F/ w0073f00.htm\#toc.

[7] The World Bank, Repositioning Nutrition as Central to Development. A Strategy for Large-Scale Action, The World Bank, Washington, DC, USA, 2006, https://openknowledge.worldbank. org/bitstream/handle/10986/7409/347750PAPER0Re101OFFICI AL0USE0ONLY1.pdf?sequence $=1$ \&isAllowed $=\mathrm{y}$.

[8] World Health Organization, Factsheet: Obesity and Overweight, World Health Organization, Geneva, Switzerland, 2020, http://www.who.int/en/newsroom/fact_sheets/detail/ obesityand_over_weight.

[9] K. H. Collins, W. Herzog, G. Z. Mac Donald et al., "Obesity, metabolic syndrome, and musculoskeletal disease: common inflammatory pathways suggest a central role for loss of muscle integrity," Frontiers in Physiology, vol. 9, pp. 1-25, Article ID 112, 2018.

[10] L. Chevallier, Nutrition: Principes et Conseils, Elsevier Masson, Paris, France, 3rd edition, 2009.

[11] A. M. Prentice, "The emerging epidemic of obesity in developing countries," International Journal of Epidemiology, vol. 35, no. 1, pp. 93-99, 2006.
[12] L. C. Fernald, J. P. Gutierrez, L. M. Neufeld et al., "High prevalence of obesity among the poor in Mexico," Jama, vol. 291, no. 21, pp. 2544-2550, 2004.

[13] Ministère de la Santé, Enquête sur la Population et la Santé Familiale-2018, Ministère de la Santé, Rabat, Morocco, 2018, https://www.unicef.org/morocco/media/1626/file/Enqu\%C3\% AAte\%20Nationale\%20sur\%20La\%20Population\%20et\%20la\% 20Sant\%C3\%A9\%20Familiale\%20(ENPSF\%20-2018).pdf.

[14] Ministère de la Santé, Enquête sur la Population et la Santé Familiale 2003-2004, Ministère de la Santé, Rabat, Morocco, 2005, http://dhsprogram.com/pubs/pdf/FR155/FR155.pdf.

[15] W. G. Cochran, Sampling Techniques, Wiley \& Sons, New York, NY, USA, 3rd edition, 1977.

[16] P. Ardilly, Les Techniques de Sondage, Edition Technip, Paris, France, 2nd edition, 2006.

[17] World Health Organization, "Obesity: preventing and managing the global epidemic," Technical Report Series, No. 894, WHO, Geneva, Switzerland, 2000.

[18] National Institutes of Health, "National Heart Lung and Blood Institute, clinical guidelines on the identification, evaluation, and treatment of overweight and obesity in adults: the evidence report," Obesity Research, vol. 6, no. 2, pp. S51-S210, 1998.

[19] WHO, WHO STEP Wise Approach to Surveillance (STEPS), World Health Organization (WHO), Geneva, Switzerland, 2008.

[20] M. C. Dop, C. Milan, A. M N'Diaye, and C. N'Diaye, “The 24hour recall for Senegalese weanlings: a validation exercise," European Journal of Clinical Nutrition, vol. 48, no. 9, pp. 643-653, 1994.

[21] E. Thompson and A. F. Subar, "Dietary assessment methodology: chapter 1," in Nutrition in the Prevention and Treatment of Disease, pp. 5-46, Academic Press, Cambridge, MA, USA, 2107.

[22] K. S. Stote, S. V. Radecki, A. J. Moshfegh, L. A. Ingwersen, and D. J. Baer, "The number of $24 \mathrm{~h}$ dietary recalls using the US department of agriculture's automated multiple-pass method required to estimate nutrient intake in overweight and obese adults," Public Health Nutrition, vol. 14, no. 10, pp. 1736-1742, 2011.

[23] S. Herceberg, M. Deheeger, and P. Preziosi, "Portions alimentaires: manuel photos pour l'estimation des quantités," Broché, vol. 14, 2002.

[24] K. Elmoumni, E. Maimouni, G. Dufourny et al., Haute Ecole Lucia de Brouck'ere-CIRIHA. Département de Diététique et Nutrition Appliquée, Bruxelles, Belgium, 2008.

[25] Nutrilog, "Database", 2016, http://www.nutrilog.com/nutrilog_fr/nutrilog_databases.htm.

[26] A. Ghasem and S. Zahediasl, "Normalitytestsforstatisticalanalysis: aguidefornon-statisticians," International Journal of Endocrinology Metabolism, vol. 10, no. 2, pp. 486-489, 2012.

[27] Haut-Commissariat au Plan, Les Indicateurs Sociaux 2012-2013, édition 2016, Haut-Commissariat au Plan, Casablanca, Morocco, 2016, https://www.hcp.ma/region-drda/attachment/834.

[28] A. Jafri, M. Jabari, M. Dahhak, R. Saile, and A. Derouiche, "Obesity and its related factors among women from popular neighborhoods in Casablanca, Morocco," Ethnicity and Disease, vol. 23, no. 3, pp. 369-373, 2013.

[29] S. Rahim and A. Baali, "Etude de l'obésité et quelques facteurs associés chez un groupe de femmes marocaines résidentes de la ville de Smara (sud du Maroc)," Antropo, vol. 24, pp. 43-53, 2011.

[30] A. Gartner, J. El Ati, P. Traissac et al., "A double burden of overall or central adiposity and anemia or iron deficiency is 
prevalent but with little socioeconomic patterning among Moroccan and Tunisian urban women," The Journal of $\mathrm{Nu}$ trition, vol. 144, no. 1, pp. 87-97, 2013.

[31] F. Barich, F. E. Zahrou, F. Z. Laamiri et al., "Association of obesity and socioeconomic status among women of childbearing age living in urban area of Morocco," Journal of Nutrition and Metabolism, vol. 2018, Article ID 6043042, 6 pages, 2018

[32] F. Z. Laamiri, N. Hasswane, A. Kerbach et al., "Risk factors associated with a breast cancer in a population of Moroccan women whose age is less than 40 years: a case control stud," Pan Africa in Medical Journal, vol. 24, pp. 1-10, 2016.

[33] Ministère de la Santé, Stratégie Multisectorielle de Prévention et de Contrôle des Maladies Non Transmissibles 2016-2025, Ministère de la Santé, Rabat, Morocco, 2016.

[34] WHO and Regional Office for the Eastern Mediterranean, Document Technique Stratégie Régionale sur la Nutrition 20102019, WHO Regional Office for the Eastern Mediterranean, Cairo, Egypt, 2010, http://applications.emro.who.int/docs/ EM_RC57_4_fr.pdf.

[35] FAO, Agriculture, Alimentation et Nutrition en Afrique: Un Ouvrage de référence à l'usage des Professeurs d'agriculture, FAO, Rome, Italy, 2002, http://www.fao.org/3/w0078fof. htm\#bm15.1.

[36] K. W. Dodd, P. M. Guenther, L. S. Freedman et al., "Statistical methods for estimating usual intake of nutrients and foods: a review of the theory," Journal of the American Dietetic Association, vol. 106, no. 10, pp. 1640-1650, 2006.

[37] S. G. Forrestal, "Energy intake misreporting among children and adolescents: a literature review," Maternal \& Child $\mathrm{Nu}$ trition, vol. 7, no. 2, pp. 112-127, 2011.

[38] J. Maurer, D. L. Taren, P. J. Teixeira et al., "The psychosocial and behavioral characteristics related to energy misreporting," Nutrition Reviews, vol. 64, no. 2, pp. 53-66, 2006.

[39] French Institute of Nutrition, Abords Méthodologiques des Enquêtes de Consommation Alimentaire Chez l'homme, French Institute of Nutrition, Bobigny, France, 1996, http:// alimentation-sante.org/wp-content/uploads/2011/07/dossierscient-8.pdf.

[40] J. Dwyer, M. F. Picciano, and D. J. Raiten, "Estimation of usual intakes: what we eat in America-NHANES," The Journal of Nutrition, vol. 133, no. 2, pp. 609S-623S, 2003.

[41] J. A. Novotny, W. V. Rumpler, and H. Riddick, "Personality characteristics as predictors of underreporting of energy intake on 24-hour dietary recall interviews," Journal of the American Dietetic Association, vol. 103, no. 29, pp. 1146-1151, 2003.

[42] R. C. Klesges, L. H. Eck, and J. A. W. Ray, "Who underreports dietary intake in a dietary recall? Evidence from the second national health and nutrition examination survey," Journal of Consulting and Clinical Psychology, vol. 63, no. 3, pp. 438-444, 1995.

[43] M. N. Bassett, D. Romaguera, and N. Samman, "Nutritional status and dietary habits of the population of the Calchaqui valleys of Tucuman, Argentina," Nutrition, vol. 27, no. 11-12, pp. 1130-1135, 2011.

[44] J. S. Shim, K. Oh, and H. C. Kim, "Dietary assessment methods in epidemiologic studies," Epidemiology and Health, vol. 36, 2014.

[45] N. P. Steyn, J. H. Nel, W. Parker, R. Ayah, and D. Mbithe, "Urbanisation and the nutrition transition: a comparison of diet and weight status of South African and Kenyan women," Scandinavian Journal of Public Health, vol. 40, no. 3, pp. 229-238, 2012.
[46] S. Zaghloul, S. N. Al-Hooti, N. Al-Hamad et al., "Evidence for nutrition transition in Kuwait: over-consumption of macronutrients and obesity," Public Health Nutrition, vol. 16, no. 4, pp. 596-607, 2012.

[47] WHO and FAO, "Diet, nutrition and the prevention of chronic diseases, report of a Joint WHO/FAO expert consultation," Technical Report Series No. 916, World Health Organization, Geneva, Switzerland, 2003.

[48] WHO, Diet, Nutrition and the Prevention of Chronic Diseases, WHO, Geneva, Switzerland, 2002.

[49] R. A. G. Souza, E. M. Yokoo, R. Sichieri, and R. A. Pereira, "Energy and macronutrient intakes in Brazil: Results of the first nationwide individual dietary survey," Public Health Nutrition, vol. 18, no. 17, pp. 3086-3095, 2015.

[50] J. Saizonou, C. S. Jerome, C. Maiga, A. Kpozehouen, M. N. Paraiso, and E. M. D. Ouendo, "Lesapport salimentairesenferchezlafemmeenagerdeprocréerdanslacom muned'OuidaauBenin," Revue marocaine de santé publique, vol. 4, no. 7, pp. 7-12, 2017.

[51] M. Afssa, Ambroise, Les Apports Nutritionnels de la Population Française, Lavoisier, Paris, France, 3rd edition, 2001.

[52] Institute Of Medicine, Les Apports Nutritionnels de Référence (ANREF): Le Guide Essentiel des Besoins en Nutriments, editor, The National Academies Press, Washington, DC, USA, 2006.

[53] Direction du Ministère de l'intérieur et des Collectivités Locales, La Région de Rabat-Salé-Kenitra, Direction du Ministère de l'intérieur et des Collectivités Locales, Quezon, Philippines, 2015, http://file://C:/Users/pc/Downloads/MON OGRAPHIE\%20DE\%20LA\%20REGION\%20DE\%20RABAT \%20SALE\%20\%20KENITRA\%20FR\%20(1).pdf.

[54] F. Allali, "Evolution des pratiques alimentaires au Maroc," International Journal of Medicine and Surgery, vol. 4, pp. 70-73, 2017.

[55] L. A. Te Morenga, A. J. Howatson, R. M. Jones, and J. Mann, "Dietary sugars and cardiometabolic risk: systematic review and meta-analyses of randomized controlled trials of the effects on blood pressure and lipids," The American Journal of Clinical Nutrition, vol. 100, no. 1, pp. 65-79, 2014.

[56] A. M. Salter, "Dietary fatty acids and cardiovascular disease," Animal, vol. 7, no. 1, pp. S163-S171, 2013.

[57] R. P. Mensink, P. L. Zock, A. D. Kester, and M. B. Katan, "Effects of dietary fatty acids and carbohydrates on the ratio of serum total to HDL cholesterol and on serum lipids and apolipoproteins: a meta-analysis of 60 controlled trials," The American Journal of Clinical Nutrition, vol. 77, no. 5, pp. 1146-1155, 2003.

[58] C. D. Fryar, J. D. Wright, M. S. Eberhardt, and B. A. Dye, "Trends in nutrient intakes and chronic health conditions among Mexican-American adults, a 25-year profile: United States 1982-2006," National Health Statistics Reports, vol. 50, pp. 1-21, 2012.

[59] S. Gopalan, "Malnutrition: causes, conséquences and solutions," Nutrition, vol. 16, no. 7-8, pp. 556-658, 2000.

[60] E. Van de Poel, A. R. Hosseinpoor, N. Speybroeck, T. V. Ourti, and J. Vega, "Socioeconomic inequality in malnutrition in developing countries," Bulletin of the World Health Organization, vol. 86, no. 4, pp. 282-291, 2008.

[61] K. Ivanovitch, J. Klaewkla, R. Chongsuwat, C. Viwatwongkasem, and W. Kitvorapat, "The intake of energy and selected nutrients by Thai urban sedentary workers: an evaluation of adherence to dietary recommendations," Journal of Nutrition and Metabolism, vol. 2014, Article ID 145182, 17 pages, 2014.

[62] M. Jessri, W. Y. Lou, and M. R. L’Abbé, "Evaluation of different methods to handle misreporting in obesity research: 
evidence from the Canadian national nutrition survey," British Journal of Nutrition, vol. 115, no. 1, pp. 147-159, 2016.

[63] I. Romieu, L. Dossus, L. Dossus et al., "Energy balance and obesity: what are the main drivers?" Cancer Causes \& Control, vol. 28 , no. 3, pp. 247-258, 2017.

[64] Organisation Mondiale de la Sante, obésité et surpoids les principaux faits, Organisation Mondiale de la Santé, Geneva, Switzerland, 2017, http://www.who.int/fr/news-room/factsheets/detail/obesity-and-overweight.

[65] Organisation Mondiale de la Sante, Suivi des Progrès 2017 Dans la Lutte Contre les Maladies Non Transmissibles, Organisation Mondiale de la Santé, Geneva, Switzerland, 2017. 